\title{
Influence of Hemodynamic Forces on Vascular Endothelial Function \\ In Vitro Studies of Shear Stress and Pinocytosis in Bovine Aortic Cells
}

\author{
Peter F. Davies, C. Forbes Dewey, Jr., \\ Steven R. Bussolari, Ethel J. Gordon, \\ and Michael A. Gimbrone, Jr. \\ Vascular Pathophysiology Laboratory, Department of Pathology, \\ Brigham and Women's Hospital, Harvard Medical School, \\ Boston, Massachusetts 02115; Fluid Mechanics Laboratory, \\ Department of Mechanical Engineering, Massachusetts Institute \\ of Technology, Cambridge, Massachusetts 02139
}

A

bstract. The relationships between fluid shear stress, a physiologically relevant mechanical force in the circulatory system, and pinocytosis (fluid-phase endocytosis) were investigated in cultured bovine aortic endothelial cells using a specially designed apparatus. Continuous exposure to steady shear stresses $\left(1-15 \mathrm{dyn} / \mathrm{cm}^{2}\right)$ in laminar flow stimulated time- and amplitude-dependent increases in pinocytotic rate which returned to control levels after several hours. After $48 \mathrm{~h}$ continuous exposure to steady shear stress, removal to static conditions also resulted in a transient increase in pinocytotic rate, suggesting that temporal fluctuations in shear stress may influence endothelial cell function. Endothelial pinocytotic rates remained constant during exposure to rapidly oscillating shear stress at near physiological frequency (1 $\mathrm{Hz}$ ) in laminar flow. In contrast, however, a sustained elevation of pinocytotic rate occurred when cells were subjected to fluctuations in shear stress amplitude (3-13 $\left.\mathrm{dyn} / \mathrm{cm}^{2}\right)$ of longer cycle time (15 min), suggesting that changes in blood flow of slower periodicity may influence pinocytotic vesicle formation. As determined by $\left[{ }^{3} \mathrm{H}\right]-$ thymidine autoradiography, neither steady nor oscillating shear stress stimulated the proliferation of confluent endothelial cells. These observations indicate that: $(a)$ alterations in fluid shear stress can significantly influence the rate of formation of pinocytotic vesicles in vascular endothelial cells, $(b)$ this process is force- and time-de-

Received for publication 19 October 1983.

J. Clin. Invest.

(c) The American Society for Clinical Investigation, Inc.

0021-9738/84/04/1121/09 \$1.00

Volume 73, April 1984, 1121-1129 pendent and shows accommodation, $(c)$ certain patterns of fluctuation in shear stress result in sustained elevation of pinocytotic rate, and $(d)$ shear stresses can modulate endothelial pinocytosis independent of growth stimulation. These findings are relevant to $(i)$ transendothelial transport and the metabolism of macromolecules in normal endothelium and (ii) the role of hemodynamic factors in the localization of atherosclerotic lesions in vivo.

\section{Introduction}

In the systemic and pulmonary circulations, vascular endothelial cells comprise the interface between flowing blood and vessel wall, and thus, are subjected to a wide variety of hemodynamic factors. A major component of these is wall shear stress, the tractive force produced by flowing blood upon the endothelial cell surface. This particular hemodynamic factor has been implicated in the atherosclerotic process because a strong correlation exists between the location of developing arterial lesions and regions where large variations in wall shear stress occur $(1,2)$. Endothelial desquamation is not required to initiate the development of focal atherosclerotic lesions $(3,4)$. It is likely, therefore, that more subtle changes, which compromise normal endothelial function $(4,5)$, are involved in early focal atherogenesis. A prominent candidate for the induction of endothelial dysfunction (6) is hemodynamic shear stress.

The development of specialized in vitro experimental systems (7) has been necessary to allow more precise studies of the relationships between shear forces and endothelial cell biology. For this purpose, we have recently developed a cone-plate apparatus in which cultured endothelial cells can be exposed to defined shear stresses comparable with those encountered in vivo for intervals varying from minutes to days (7-9). Significant shear-induced alterations in endothelial cell shape and cytoskeletal organization have been observed in this experimental system $(7,10,11)$. In the studies reported here, the apparatus 
has been used to investigate the influence of shear stresses upon a fundamental cellular process, pinocytosis (fluid-phase endocytosis), which is the uptake of extracellular fluid via plasmalemmal vesicles.

Endothelial cells have large numbers of plasmalemmal invaginations and vesicles, some of which participate in the transport of fluid and macromolecules across the endothelial barrier $(12,13)$, while others deliver exogenous substances to the lysosomal degradation system of the cell $(14,15)$. The initial infolding of cell membrane to form an endocytic vesicle may be influenced by the distribution of physical forces along the cell surface; thus, fluid flow may modify the rate or nature of vesicle formation. The observations reported here indicate that the rate of pinocytosis in cultured endothelial cells is sensitive to applied fluid shear stresses and that the cells appear to undergo a complex process of accommodation to the shear stress. These in vitro observations suggest that hemodynamic factors such as shear stress can significantly influence vascular endothelial function in vivo.

\section{Methods}

Shear stress. The theory and design of the shear stress apparatus, which utilizes the geometry of a cone-plate viscometer, has been fully described elsewhere $(7,8)$. Fluid shear stress was produced by rotation of a shallow cone with respect to a stationary base plate that contained 12 glass coverslips of cultured endothelial monolayers. The unit, contained within a plexiglass chamber, was sterilized before use with ethylene oxide gas. Stable plate temperature $\left(37^{\circ} \pm 0.3^{\circ} \mathrm{C}\right)$ and controlled chamber atmosphere were provided by resistance heaters and humidified gas $(5 \%$ $\mathrm{CO}_{2}: 95 \%$ air), respectively.

The cone angle used in the shear stress experiments described here was $0.5^{\circ}$. Rotational speeds up to $160 \mathrm{rpm}$ were used with tissue culture medium having fluid viscosity of $7.6 \times 10^{-3} \mathrm{~cm} / \mathrm{sec}$. This combination of viscosity, cone angle, and rotational speed produced shear stresses in the range of $0-15 \mathrm{dyn} / \mathrm{cm}^{2}$. For experiments exceeding several hours, fresh culture medium was continuously infused $(3 \mathrm{ml} / \mathrm{h})$ to maintain constant osmolarity and nutrient concentrations. Shear stress was applied to endothelial monolayers in three different patterns: $(a)$ Steady shear stress was applied as a constant force of $1,5,8$, or $15 \mathrm{dyn} / \mathrm{cm}^{2}$ throughout the time periods indicated in each experiment. (b) Periodic shear stress involved the application of shear stress in square wave cycles of long duration ( 5 or $15 \mathrm{~min}$ ) between a low $\left(0,1\right.$, or $\left.3 \mathrm{dyn} / \mathrm{cm}^{2}\right)$ and a higher ( 8 or $13 \mathrm{dyn} / \mathrm{cm}^{2}$ ) amplitude. For example, cells were exposed to 3 $\mathrm{dyn} / \mathrm{cm}^{2}$ for $15 \mathrm{~min}$ before an abrupt increase to $13 \mathrm{dyn} / \mathrm{cm}^{2}$ for 15 min followed by another period of exposure at the lower amplitude, and so on. (c) Oscillating shear stress was a special case of periodic shear stress, being a rapid sinusoidal change of shear stress at $60 \mathrm{cycles} / \mathrm{min}$ ( $1 \mathrm{~Hz}$ ) between 3 and $13 \mathrm{dyn} / \mathrm{cm}^{2}$ (time average shear stress, $8 \mathrm{dyn} /$ $\mathrm{cm}^{2}$ ). This condition was obtained by tilting the cone with respect to the axis of rotation to produce a slight wobble in the cone rotation. The frequency of these oscillations approximated that of the mammalian cardiac cycle.

Endothelial cells. Bovine aortic endothelial cells (BAEC) ${ }^{1}$ were isolated from calf aorta using techniques described fully elsewhere (16), and were

1. Abbreviations used in this paper: BAEC, bovine aortic endothelial cells; HRP, horseradish peroxidase. cultured in Dulbecco's Modified Eagles Medium with 10\% calf serum (M.A. Bioproducts, Walkersville, MD) supplemented with $2 \mathrm{mM}$ glutamine and $100 \mathrm{U}$ each of penicillin and streptomycin per milliliter. Cells of a single strain (11-BAEC) between passages 14 and 20 were used in these studies. Cell suspensions were replicate-plated on 12-mm diameter glass coverslips (Bellco No. 1, $0.15 \mathrm{~mm}$ thickness; Bellco Glass, Inc., Vineland, NJ) where they grew to confluence under standard culture conditions. At confluence, the cells were growth-inhibited as revealed by low $\left[{ }^{3} \mathrm{H}\right]$ thymidine labelling $(<6 \%) .12$ coverslip cultures were placed in the apparatus for each experiment. The biological compatibility of the shear stress apparatus with BAEC has been previously established (7). For each group of test monolayers subjected to shear stress, control monolayers from the same batch of cells were maintained under static conditions ( 0 shear).

Pinocytosis (fluid endocytosis). Horseradish peroxidase (HRP, isoenzyme Type VI; Sigma Chemical Co., St. Louis, MO) was used to measure the rate of bulk fluid uptake into endothelial pinocytotic vesicles. Cellular HRP was determined spectrophotometrically by the procedure of Steinman and Cohn (17) using $\sigma$-dianisidine and hydrogen peroxide as substrate. The protocol for endothelial cells was as previously described (15). HRP was injected into the apparatus at a concentration of 40 $\mathrm{mg} / \mathrm{ml}$ to give a final concentration of $2 \mathrm{mg} / \mathrm{ml}$ culture medium. This concentration was verified by removing an aliquot of the final media from both test and control systems for assay of HRP activity at the beginning and end of incubation. Any small differences in HRP concentrations (range $1.91-2.17 \mathrm{mg} / \mathrm{ml}$ ) were corrected by normalizing the rate of HRP uptake to a medium concentration of $2 \mathrm{mg} / \mathrm{ml}$. This is valid because HRP is distributed uniformly in the medium and does not adsorb to cells $(15,17)$ or to siliconized surfaces of the apparatus (P. F. Davies, unpublished observations). HRP uptake was measured for up to $2 \mathrm{~h}$. During this time cellular accumulation is proportional to pinocytic rate; after about $3 \mathrm{~h}$ of continuous HRP entry into the cell, the uptake curves begin to plateau reflecting significant lysosomal degradation $(17,18)$.

Ultrastructural cytochemical localization of HRP. After exposure to shear stress in the presence of HRP, endothelial cells were washed five times with Hanks' balanced salt solution (HBSS, M.A. Bioproducts) containing $0.2 \%$ bovine serum albumin, rinsed twice with HBSS, and then fixed with $3 \%$ glutaraldehyde in $0.1 \mathrm{M}$ cacodylate buffer with $0.05 \%$ $\mathrm{CaCl}_{2}$. Peroxidase activity was localized in the cells by a modification of the histochemical technique of Graham and Karnovsky (19). The cells were preincubated for $30 \mathrm{~min}$ in $50 \mathrm{mg} / 100 \mathrm{ml}$ diaminobenzidine in $0.05 \mathrm{M}$ Tris- $\mathrm{HCl}$ at $\mathrm{pH}$ 7.6. $\mathrm{H}_{2} \mathrm{O}_{2}$ was then added to the diaminobenzidine to a final concentration of $0.01 \%$ for $30 \mathrm{~min}$. After rinsing with cacodylate buffer, cells were postfixed in $1 \% \mathrm{OsO}_{4}$, dehydrated, and embedded in Epon 812 directly in the petri dish. After polymerization, the cells were remounted on Epon blanks and cut transversely or en face. Thin sections were examined in a Philips 201 electron microscope (Philips Electronic Instruments, Inc., Mahwah, NJ).

$\left[{ }^{3} \mathrm{H}\right]$ Thymidine autoradiography of endothelial cells. After exposure to shear or static conditions, coverslips of endothelial cells were removed to a petri dish where they were incubated in culture medium containing $0.3 \mu \mathrm{Ci}\left[{ }^{3} \mathrm{H}\right]$ thymidine $/ \mathrm{ml}$. After $24 \mathrm{~h}$ of continuous incubation at $37^{\circ} \mathrm{C}$, cells were washed twice with HBSS, fixed in ethanol:acetic acid (2:1, $\mathrm{vol} / \mathrm{vol}$ ) for $10 \mathrm{~min}$, rinsed with deionized water, and air dried. Each monolayer was overlayed with NTB2 emulsion (Eastman Kodak Co., Rochester, NY) and exposed at $4^{\circ} \mathrm{C}$ for $5 \mathrm{~d}$. Silver grains derived from radioactive nuclei were developed on the film in situ and the cell nuclei were counterstained with hematoxylin. The fraction of radiolabeled nuclei 
was counted directly by light microscopy at a power of $\times 100$. A total of 1,000 cells were counted in five regions of each coverslip.

\section{Results}

Application of shear stresses to cultured endothelial monolayers. The movement of a viscous fluid over an endothelial cell monolayer results in a tractive horizontal force applied to the cell surface. The force per unit surface area is defined as shear stress. Both in vivo and under the conditions of our experiments in vitro, the shear stresses acting upon the endothelium depend only upon the fluid viscosity and the detailed distribution of flow velocities near the cell surface (8), as shown schematically in Fig. 1. The in vitro approach used here allows the prolonged application of varying amplitudes of shear stress to endothelial cells maintained in a defined chemical milieu. Previous morphological studies performed in this system have shown that 24-48-h exposure of endothelial cell monolayers to a steady shear stress of 5-8 dyn $/ \mathrm{cm}^{2}$ results in shape change (polygonal to ellipsoidal) and alignment of the cells in the direction of the applied force (7). As demonstrated below, alterations in pinocytosis occur earlier than shape change and cell alignment and at shear stress amplitudes lower than those required for detectable morphological change.

Pinocytosis is initially time- and shear-dependent. When confluent BAEC were exposed to steady shear stresses varying in amplitude between 0 and $15 \mathrm{dyn} / \mathrm{cm}^{2}$, there was a time- and force-dependent increase of fluid phase endocytosis, as measured by HRP uptake, during the first hours of exposure (Fig. $2 \mathrm{~A}$ ). Shear stress at $1 \mathrm{dyn} / \mathrm{cm}^{2}$, an amplitude that fails to align endothelial cells in vitro after prolonged application, resulted in a small elevation of HRP uptake by $2 \mathrm{~h}$. A higher rate of pi- nocytosis was reached during 1 -h exposure to $15 \mathrm{dyn} / \mathrm{cm}^{2}$ than during $2 \mathrm{~h}$ exposure to $8 \mathrm{dyn} / \mathrm{cm}^{2}$. A maximum increase of four- to fivefold over static control cells was observed during the first hour of exposure to $15 \mathrm{dyn} / \mathrm{cm}^{2}$, whereas the second hour of exposure to HRP resulted in only a small further increase. To further investigate the period immediately following the initial increase of pinocytosis, sequential 2-h time frames were analyzed during $8 \mathrm{~h}$ of steady shear of $8 \mathrm{dyn} / \mathrm{cm}^{2}$. As shown in Fig. 2 $B$, after an initial doubling of HRP uptake during the first $2 \mathrm{~h}$, there was a marked inhibition of HRP uptake to $46 \%( \pm 3)$ that of static controls during the period between 2 and $4 \mathrm{~h}$ of shear stress. This was followed during the subsequent $4 \mathrm{~h}$ by a return towards control levels $(4-6 \mathrm{~h}, 127 \% \pm 15 ; 6-8 \mathrm{~h}, 85 \% \pm 7)$. Pinocytosis rates measured $40 \mathrm{~h}$ later confirmed a sustained return to control levels $(91 \% \pm 11)$. The shape of the stimulation-inhibition cycle reported in Fig. $2 B$ bears a striking resemblance to the relaxation-oscillation cycle of a damped mechanical system.

Step-decrease in the magnitude of shear also results in transient elevation of pinocytosis. As noted in Fig. $2 \mathrm{~B}$, after $48 \mathrm{~h}$ of exposure to steady shear of $8 \mathrm{dyn} / \mathrm{cm}^{2}$, endothelial pinocytotic rates returned to control levels. When, however, such endothelium was returned to static conditions ( 0 shear stress), there was also a transient rise in the rate of pinocytosis (Fig. 3). In cells exposed to steady shear stress for $48 \mathrm{~h}$ before introduction of HRP for a further $2 \mathrm{~h}$ at $8 \mathrm{dyn} / \mathrm{cm}^{2}$ (group D), pinocytotic rates were not significantly different $(102 \% \pm 8)$ from control levels (cells at 0 shear stress for $50 \mathrm{~h}$, group A). Step-up from 0 to $8 \mathrm{dyn} / \mathrm{cm}^{2}$ for $2 \mathrm{~h}$ (group B) or step-down from 8 to 0 $\mathrm{dyn} / \mathrm{cm}^{2}$ for $2 \mathrm{~h}$ (group C), however, resulted in significantly elevated levels of pinocytosis $(190 \% \pm 31$ and $170 \% \pm 23$, respectively). In a similar experiment, step-down from $8 \mathrm{dyn} / \mathrm{cm}^{2}$ after

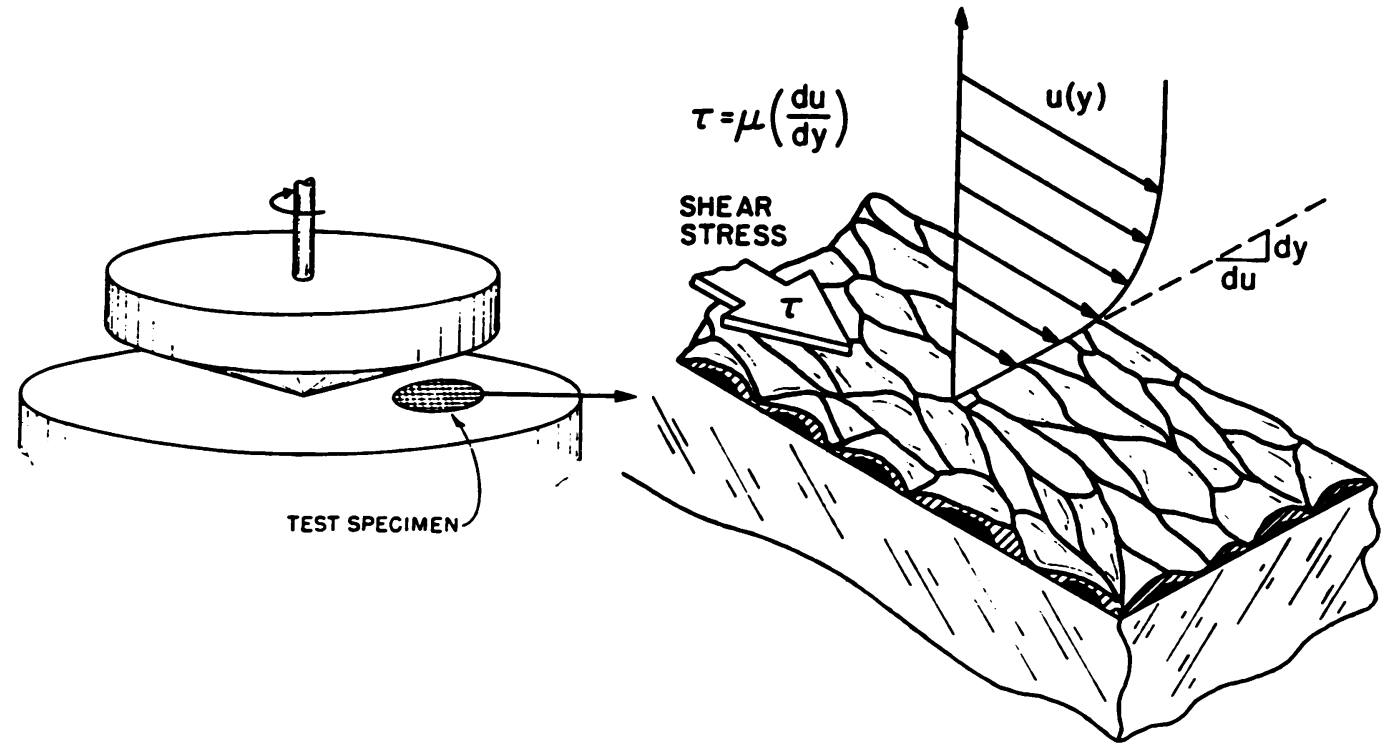

Figure 1. Diagram of the essential components of the shear stress apparatus. A rotating cone applies fluid shear stress to endothelial cell monolayers maintained on glass coverslips. The shear stress force $(\tau)$ depends upon the fluid viscosity $(\mu)$ and the detailed distribution of flow velocities near the cell surface as shown schematically. 

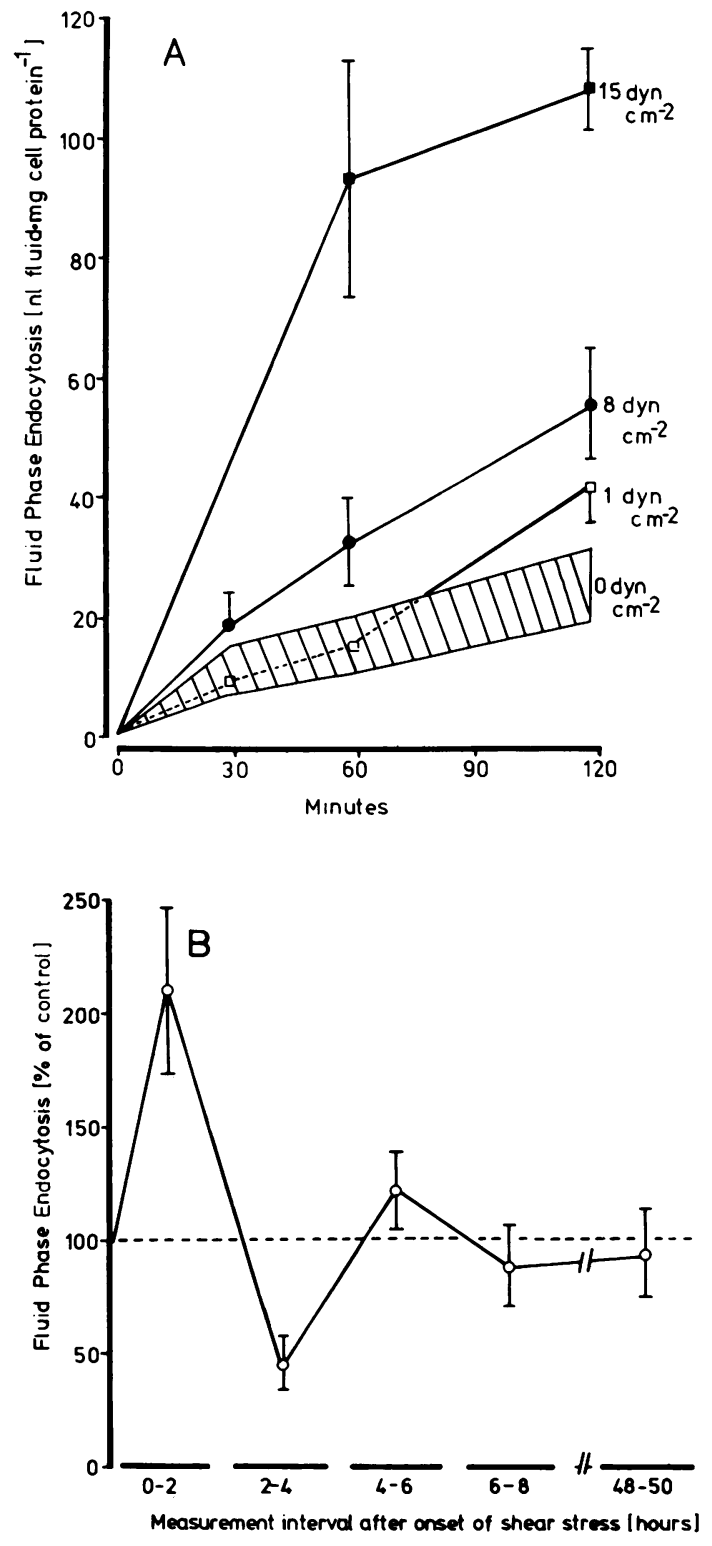

Figure 2. (A) Influence of steady shear stress upon fluid-phase endocytosis in confluent endothelial monolayers as measured by HRP uptake. 5 min after the imposition of shear stress, HRP was injected into the culture medium (time 0 ). Coverslips were withdrawn at intervals for the assay of cellular HRP uptake. Control coverslips $(0$ $\mathrm{dyn} \cdot \mathrm{cm}^{-2}$ ) were maintained in plastic petri dishes. Each coverslip contained $\sim 2 \times 10^{5}$ endothelial cells. Each point is the mean of four measurements \pm SD. $(B)$ Fluid-phase endocytosis measured at various intervals during exposure of confluent endothelium to shear stress at $8 \mathrm{dyn} \cdot \mathrm{cm}^{-2}$. Each point is a separate experiment in which cellular HRP uptake was expressed as a percentage $( \pm \mathrm{SD})$ of that of a matched control $\left(0 \mathrm{dyn} \cdot \mathrm{cm}^{-2}\right)$. HRP was injected at the appropriate time $(0,2,4,6$, and $48 \mathrm{~h})$ after the imposition of shear stress. Each experiment was terminated $2 \mathrm{~h}$ later, the coverslips removed and assayed for cellular HRP uptake.

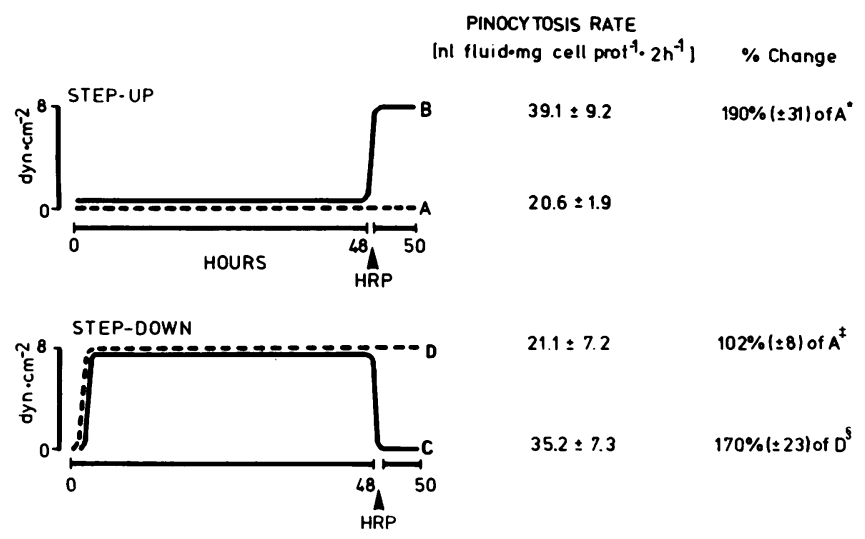

Figure 3. Effects of 48-h exposure and step-change of shear stress upon endothelial pinocytosis. Endothelial monolayers were maintained for $48 \mathrm{~h}$ at 0 or $8 \mathrm{dyn} \cdot \mathrm{cm}^{-2}$ (groups A and D). HRP was injected into the culture medium and its cellular uptake was measured over a 2-h period. Step change was induced by either increasing shear stress from 0 to $8 \mathrm{dyn} \cdot \mathrm{cm}^{-2}$ (step-up; group B) or removing endothelial monolayers from the apparatus (step-down; group C). HRP uptake was then measured for $2 \mathrm{~h}$. * Significantly different from group A, $P<0.01$. $\ddagger$ Not significantly different from group A. § Significantly different from group $\mathrm{D}, P<0.025$.

$28 \mathrm{~h}$ also resulted in a significant elevation of HRP uptake to $227 \% \pm 44$ of control level. These experiments indicated that following accommodation to either steady shear stress or static conditions, pinocytotic rates were equal, i.e., independent of the absolute level of shear stress, and confirmed that changes in steady shear stress levels resulted in transiently increased pinocytotic rates.

Slow periodic shear stress increases pinocytotic rate. In attempts to magnify the effects of step changes in shear stress upon pinocytotic rate, confluent endothelial cells were incubated for $2 \mathrm{~h}$ with HRP under conditions where the amplitude of shear stress was periodically changed. In the first series of experiments, shear stress was abruptly changed between 1 and 8 dyn $/ \mathrm{cm}^{2}$ every $15 \mathrm{~min}$ for $2 \mathrm{~h}$ (average shear stress amplitude, $4.5 \mathrm{dyn} / \mathrm{cm}^{2}$ ). This resulted in a $51 \%$ increase of pinocytosis rate compared with stationary controls (data not shown). When the average shear stress amplitude was increased to $8 \mathrm{dyn} / \mathrm{cm}^{2}$ by alternating between 3 and $13 \mathrm{dyn} / \mathrm{cm}^{2}$ with a periodicity of $15 \mathrm{~min}$, pinocytotic rates increased to $264 \% \pm 63$ of static control levels during the first $2 \mathrm{~h}$ and did not decline significantly $(207 \% \pm 51)$ during the subsequent $6 \mathrm{~h}$ (Fig. 4). When the periodicity was reduced to $5 \mathrm{~min}$, however, HRP uptake by the endothelial cells did not increase but remained near control levels $(0-2 \mathrm{~h}, 93 \% \pm 21 ; 4-6 \mathrm{~h}, 113 \% \pm 23)$. It appears, therefore, that either a step change of steady shear stress, or periodic change of shear stress, was sufficient to invoke elevation of pinocytotic rates in confluent endothelium. As the time between change of amplitude was shortened, however, the stimulatory effect upon pinocytosis diminished even though the mean shear stress am- 


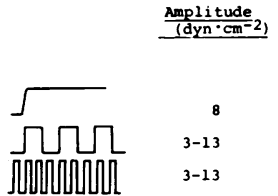

Periodic, 5-min cycle
Steady, continuous

Periodic, 15-min cycle

$$
\begin{array}{ccccc}
8 & 210 \pm 46 * 116 \pm 17 & 91 \pm 13 \\
3-13 & 264 \pm 6 * 207 \pm 51 * & \text { ND } \\
3-13 & 93 \pm 21 & 112 \pm 23 & \text { ND }
\end{array}
$$

Figure 4. Duration of effects of steady and periodic shear stresses upon fluid phase endocytosis in cultured endothelium. During periodic shear stress, cells were exposed to repeated step changes (5 or 15 min cycle) of shear stress. HRP was injected and its uptake was measured during the period indicated. *, Significantly different from control, $P<0.05$. ND, not determined.

plitude was at a level $\left(8 \mathrm{dyn} / \mathrm{cm}^{2}\right)$ that, upon steady application, would stimulate HRP uptake.

Oscillations of shear stress at physiological frequencies (1 $\mathrm{Hz}$ ) do not stimulate pinocytosis. By the use of a wobbling cone, shear stresses oscillating between 3 and $13 \mathrm{dyn} / \mathrm{cm}^{2}$ at a frequency of $60 \mathrm{cycles} / \mathrm{min}(1 \mathrm{~Hz})$ were applied to the endothelial monolayers. During a 2-h period of exposure (time average shear stress amplitude, $8 \mathrm{dyn} / \mathrm{cm}^{2}$ ), there was no significant change in pinocytotic rate as determined by cellular HRP uptake (Fig. 5) compared with static controls (0 shear stress). When the period of exposure to oscillating shear stress was increased to 4,15 , or $25 \mathrm{~h}, \mathrm{HRP}$ uptake during the final $2 \mathrm{~h}$ remained within $16 \%$ of static controls (Table I). Thus, a clear difference in the cellular response of endothelium to steady and oscillating shear stress exists, even though the time average shear stress amplitude in both cases $\left(8 \mathrm{dyn} / \mathrm{cm}^{2}\right)$ was the same.

Ultrastructural cytochemical localization of HRP. The ultrastructural distribution of HRP in endothelial cells exposed to steady shear stress and fixed during a period of elevated pinocytotic rate is illustrated in Fig. 6 . The pattern was qualitatively similar to that seen in control endothelial cells. HRP was located in membrane-bounded vesicles, endosomes, and secondary lysosomes with no indication of cytoplasmic distribution, which is consistent with previous studies $(15,17)$.

$\left[{ }^{3} \mathrm{H}\right]$ Thymidine nuclear labeling of endothelium exposed to shear. Confluent endothelial cells in culture are growth-inhibited.

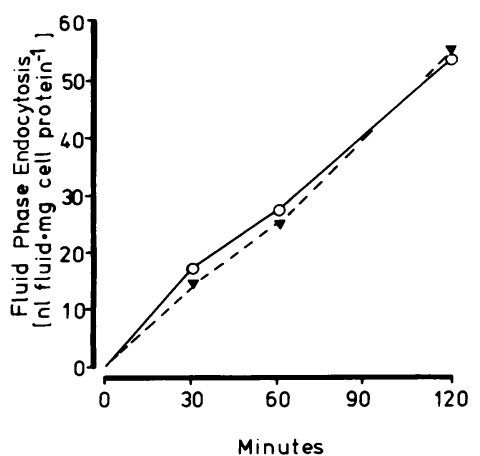

Figure 5. Influence of rapidly oscillating $(1 \mathrm{~Hz})$ laminar shear stress upon endothelial endocytosis. A wobbling cone was used to impose sinusoidal oscillating shear stress between 3 and 13 dyn $\cdot \mathrm{cm}^{-2}$ (time-average amplitude $8 \mathrm{dyn} \cdot \mathrm{cm}^{-2}$ ). Cellular HRP uptake was determined at various intervals. End point is the mean of six measure-

ments. Standard deviations were within $30 \%$ of the mean. Static conditions, $(-\circ-), 0$ dynes $\mathrm{cm}^{-2}$; oscillating shear stress, $(--\nabla--)$.
Table I. Pinocytosis in Confluent Cultured Endothelial Cells Exposed to Oscillating Shear Stress at $1 \mathrm{~Hz}$ Frequency*

\begin{tabular}{llc}
\hline Duration of exposure & $\begin{array}{l}\text { No. of experiments } \\
\text { (No. of measurements) }\end{array}$ & Pinocytotic rateł \\
\hline$h$ & & $\%$ control \\
0.5 & $4(12)$ & $83 \pm 18$ \\
1.0 & $5(15)$ & $103 \pm 18$ \\
2.0 & $7(21)$ & $100 \pm 15$ \\
4.0 & $2(12)$ & $86 \pm 3$ \\
6.0 & $2(12)$ & $85 \pm 2$ \\
15.0 & $1(6)$ & $91 \pm 17$ \\
24.0 & $1(6)$ & $108 \pm 13$
\end{tabular}

* Oscillating shear stress in laminar flow. Sinusoidal frequency, $1 \mathrm{~Hz}$. Range, 3-15 dyn $/ \mathrm{cm}^{2}$. Time average amplitude, $8 \mathrm{dyn} / \mathrm{cm}^{2}$.

$\ddagger$ Measured as cellular HRP uptake per milligram cell protein during final $2 \mathrm{~h}$ of exposure to shear stress. Expressed as percentage of value determined in control monolayers $\left(0 \mathrm{dyn} / \mathrm{cm}^{2}\right) \pm \mathrm{SD}$.

Incubation with $\left[{ }^{3} \mathrm{H}\right]$ thymidine for $24 \mathrm{~h}$ results in a low frequency of labeling of nuclear DNA as measured by autoradiography (18). When a majority of the cells are made to divide by disruption of the monolayer, increased pinocytotic rates are observed which are related to the cell cycle $(18,5)$. It was therefore important to determine whether exposure to shear stresses altered the growth patterns of confluent endothelium.

As shown in Table II, over a wide range of shear stress conditions, the fraction of labeled endothelial cell nuclei remained low $(<6 \%)$. Much of this data was obtained from the same experiments in which HRP uptake was measured. As a positive control, the percentage of labeled cells on a growing subconfluent endothelial culture was $43 \%$. We conclude, therefore, that shear stress-induced changes in pinocytic rate occurred in the absence of any significant alterations in endothelial cell growth status.

\section{Discussion}

In vivo studies conducted over many years suggest that hemodynamic forces influence arterial wall physiology and pathology in a number of ways (for reviews, see references 2023). It has been proposed that extremes of shear stress, either very high (1) or very low (20), can contribute to vessel wall pathology. Increased endothelial permeability has been measured near vessel branches and bifurcations (24), regions that are exposed to both high and low shear stresses (25). Disruption of endothelial cell alignment has been observed in areas where flow separation is expected to occur $(26,27)$, and such areas appear to be more susceptible to endothelial damage, intimal cell proliferation, and the development of athersclerotic lesions (28). Sites of highest shear stress are located near the flow dividers which tend to be spared endothelial damage and lipid deposition. These in vivo observations suggest, therefore, that both the timeaverage magnitude of wall shear stresses, as well as temporal variations in magnitude and direction, may modify endothelial function. 

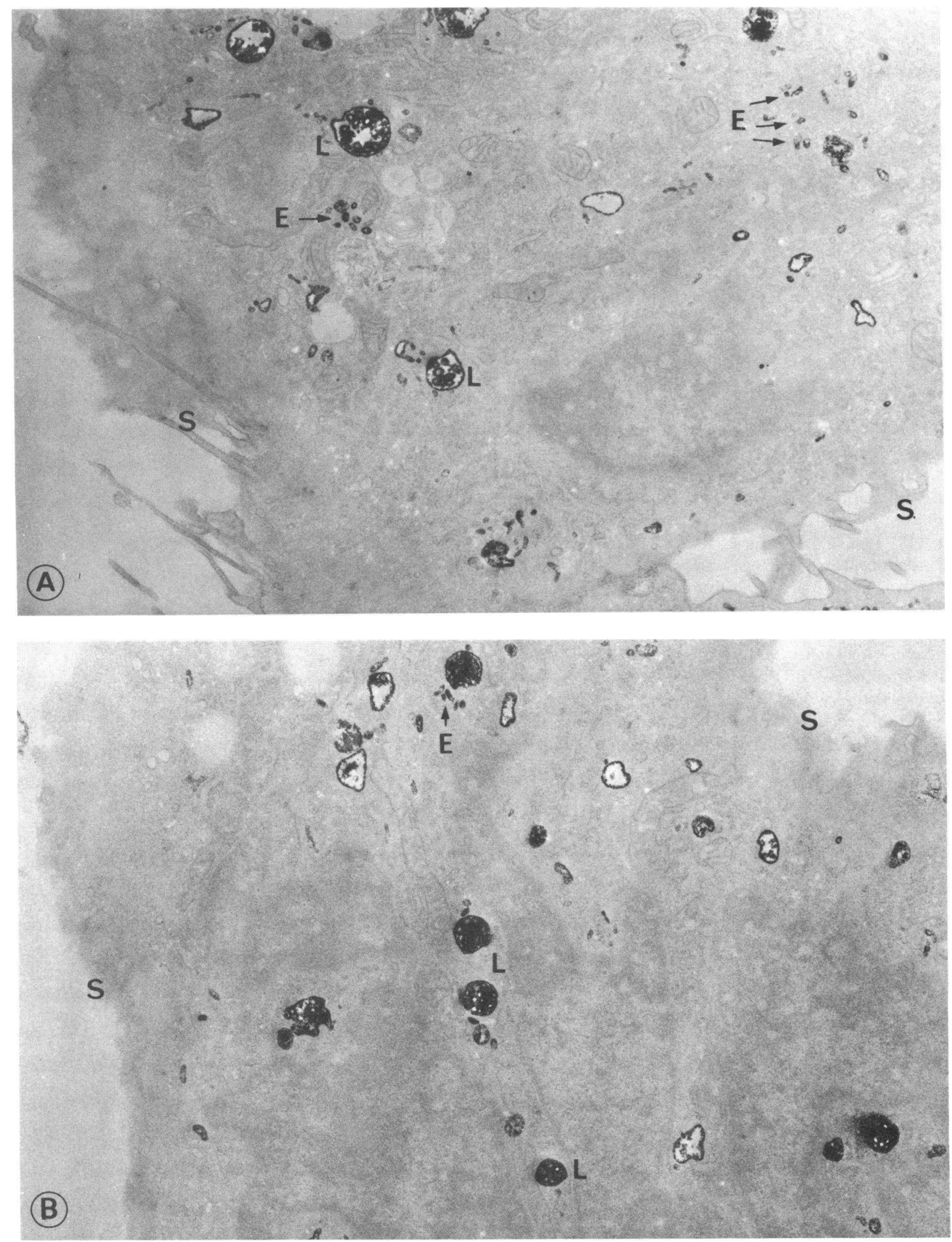

1126 Davies, Dewey, Bussolari, Gordon, and Gimbrone 
Table II. Endothelial Cell $\left[{ }^{3} \mathrm{H}\right]$ Thymidine-labeling After Exposure to Shear Stress

\begin{tabular}{|c|c|c|c|}
\hline \multirow[b]{2}{*}{$\begin{array}{l}\text { Period } \\
\text { of exposure }\end{array}$} & \multicolumn{3}{|c|}{ Percent labeled nuclei* } \\
\hline & $\begin{array}{l}\text { Steady shear } \\
8 \mathrm{dyn} / \mathrm{cm}^{2}\end{array}$ & $\begin{array}{l}\text { Steady shear } \\
15 \mathrm{dyn} / \mathrm{cm}^{2}\end{array}$ & $\begin{array}{l}\text { Oscillating shear } \\
3-13 \mathrm{dyn} / \mathrm{cm}^{2}\end{array}$ \\
\hline \multicolumn{4}{|l|}{$h$} \\
\hline 0.5 & 5 & - & - \\
\hline 2.0 & 3 & 3 & 6 \\
\hline 4.0 & 4 & 6 & - \\
\hline 8.0 & 3 & - & - \\
\hline 24.0 & 4 & - & 6 \\
\hline
\end{tabular}

Controls: static ( 0 shear) confluent monolayer, $4 \pm 2 \%$ (SD); subconfluent, growing cells ( 0 shear), $43 \pm 17 \%$ (SD).

* After exposure to shear stress, coverslips of cells were incubated with $\left[{ }^{3} \mathrm{H}\right]$ thymidine for $24 \mathrm{~h}$ and processed for auto-radiography.

This paper presents evidence that the application of shear stress to the surface of confluent endothelium in vitro can directly influence a basic endothelial cell function, fluid-phase endocytosis. Furthermore, the cells can accommodate quite rapidly to the new conditions and return to basal rates within several hours after the onset of shear. An interesting aspect of the accommodation response is the period during which pinocytosis is significantly inhibited, a phenomenon which also appears to be dependent upon the amplitude of shear stress in that it occurs within $2 \mathrm{~h}$ when the cells are exposed to $15 \mathrm{dyn} / \mathrm{cm}^{2}$ and within $4 \mathrm{~h}$ when exposed to $8 \mathrm{dyn} / \mathrm{cm}^{2}$. The removal of shear stress after long-term exposure ( $48 \mathrm{~h}$ ) also results in increased pinocytosis, suggesting that change of shear is more important than the direction of change. This is potentially important in view of the constantly changing flows of varying magnitudes in the vascular system, particularly in the major arteries (29). When the frequency of shear stress approximated quasi-physiological levels $(1 \mathrm{~Hz})$, no change in pinocytosis occurred. However, when shear stresses were applied to the endothelium periodically, pinocytotic rates in the cells increased when the time between applications of shear stress was relatively long.

The above observations can be considered to be relevant to two hemodynamic situations which occur in vivo. First, cycles of systole and diastole produce a rapid oscillatory shear stress in the arterial circulation. Maximum frequencies up to 20 cycle/s have been recorded under conditions where harmonics contribute significantly to the waveforms (Langille, L., personal communication). The amplitude of such fluctuations is greatest in the large vessels and decreases in the muscular distributing arteries because of the dampening effect of the large elastic arteries, particularly the aorta. Our oscillating shear stress experiments $(1 \mathrm{~Hz})$ are analogous to the fundamental pulse component. Second, in addition to such rapid changes of shear stress, there are components of flow-induced shear of slower periodicity induced by the geometric arrangement of blood vessels combined with poorly defined fluctuations in blood pressure that can normally occur throughout the day. For example, at branch arteries of the aorta and at bifurcations, complex hemodynamic events occur which result in a slow periodicity of change of shear close to the branch points, and even reversal of flow direction (30). These events are superimposed upon the higher frequency pulse wave. The dynamics of flow in these regions are highly susceptible to a number of external conditions (e.g., hypertension, exercise, smoking, and psychological stress). It is conceivable that our data with slow periodicity and steady shear stress are relevant to hemodynamically-induced vascular changes in these regions. Over a 24-h period, major changes of blood pressure and pulse rate occur with frequencies varying from $1 \mathrm{~h}$ to several minutes (31). There appears, therefore, to be a broad spectrum of fluctuations in hemodynamic parameters that may influence endothelial cell function.

All of the data in the present study refer to well-defined laminar flow conditions. In addition to laminar flow, however, turbulent flow occurs in certain regions of the major arterial vessels and such forces may affect endothelial morphology and function in quite different ways than does laminar flow (Remuzzi, A., C. F. Dewey, Jr., and M. A. Gimbrone, Jr., unpublished observations).

Fluid-phase endocytosis is a constitutive function of all eukaryotic cells and encompasses entry of extracellular fluid and soluble macromolecules into both coated and uncoated vesicles after which the vesicle contents may be processed in a number of ways (see references 14, 32 for review). Pinocytosis is very closely associated with the recycling of membrane to the cell surface (33), e.g., an increase of pinocytotic rate will result in faster recycling of membrane. In endothelial cells in vivo, endocytosis is implicated in the movement of plasma molecules to the interstitial subendothelial space (13). It is not clear whether increased pinocytosis will result in increased transendothelial transport because (a) some vesicles are also targeted for the endothelial lysosomes where their contents are degraded (15), and $(b)$ transport across the endothelium has not been satisfactorily measured in vitro under conditions of shear, although recent attempts to produce a functional endothelial barrier in vitro appear promising (34).
Figure 6. Ultrastructural histochemical localization of HRP in cultured BAEC exposed to $(A)$ static conditions $0 \mathrm{dyn} / \mathrm{cm}^{2}$ and $(B)$ steady shear stress of $8 \mathrm{dyn} / \mathrm{cm}^{2}$. Cells were incubated with $2 \mathrm{mg} \mathrm{HRP} / \mathrm{ml}$ for $2 \mathrm{~h}$. Cellular localization of HRP reaction product includes secondary lysosomes $(L)$ and cytoplasmic endosomes $(E)$ in transit between the cell surface $(S)$ and lysosomes. The distribution of HRP is similar in the absence and presence of shear although the magnitude of uptake in $(B)$ is more than twice that of $(A)$ as determined spectrophotometrically. En face sections. $(A) \times 14800$, (B) $\times 14400$. 
Shear stresses may influence the rate of pinocytosis in endothelium by modulating the mechanisms of pinocytotic vesicle formation. Weinbaum and Chien (35) have elegantly modeled the interactions between the vesicle membrane and the plasma membrane, i.e., vesicle detachment and attachment, the former of which may be rate-limiting for the internalization of vesicles. In such a model, it is possible that external physical forces such as shear stress directly influence the deformability of vesicle attachment sites on the apical endothelial surface. While this approach may be relevant to random vesicular movement, the formation and movement of most endothelial vesicles appears to be largely energy-dependent and related to the integrity of the cytoskeleton. Pinocytosis of bulk fluid tracers is inhibited by up to $90 \%$ by drugs which inhibit glycolysis and respiration (36). Microfilament disassembly by agents such as cytochalasins also results in significant (50\%) inhibition of pinocytosis (37). It is reasonable to postulate, therefore, that shear stress indirectly influences HRP uptake in endothelium via other metabolic and structural systems in addition to any direct physical effects upon vesicle detachment at the cell surface.

The experiments reported here measure total endocytic volume ingested by the cell without distinguishing between receptormediated and nonspecific endocytic mechanisms. Surface membrane is continuously recycled through vesicular compartments of the cell (33). The presence of specific receptors for exogenous macromolecules on the vesicular membrane is subject to control mechanisms that, in all probability, are quite separate from those which mediate membrane recycling. For example, the expression of lipoprotein receptors is governed primarily by the availability of exogenous cholesterol to the cell (38). It should not be expected a priori, therefore, that the influences of shear stress upon the endocytosis (and metabolism) of specific ligands such as low density lipoproteins will be the same as for pinocytotic rates. It is important, however, to document the changes in pinocytosis induced by shear stresses in order to interpret the endocytosis of lipoproteins; such investigations are currently underway in this laboratory (39).

In summary, we have demonstrated that a basic endothelial cell function, fluid-phase pinocytosis, is influenced by fluid shear stress under laminar flow conditions; that the frequency as well as the amplitude of the shear stress affects this response; and that under certain circumstances, the endothelium shows adaptation to new conditions of shear stress. The studies are relevant to the transendothelial transport and/or metabolic processing of macromolecules, and perhaps to other aspects of endothelial physiology and pathology in vivo.

\section{Acknowledgments}

We thank Cathy Kerr, Susan O'Connor, and Barbara Eisenhaure for expert technical assistance. We are also grateful to Dr. Lowell Langille, University of Western Ontario, Canada for discussion concerning the range and periodicity of physiological shear stress.

This research was supported by National Institutes of Health grants HL25536 and HL22602 and by the Whitaker Health Sciences Fund of the Massachusetts Institute of Technology.

\section{References}

1. Fry, D. L. 1968. Acute vascular endothelial changes associated with increased blood velocity gradients. Circ. Res. 22:165-197.

2. Fry, D. L. 1972. Response of the arterial wall to certain physical factors. Ciba Found. Symp. 12:93-110.

3. Davies, P. F., M. A. Reidy, T. B. Goode, and D. E. Bowyer. 1976. Scanning electron microscopy in the evaluation of endothelial integrity of the fatty streak lesion of atherosclerosis. Atherosclerosis. 25:125-130.

4. Goode, T. B., P. F. Davies, M. A. Reidy, and D. E. Bowyer. 1977. Aortic endothelial cell morphology observed in situ by scanning electron microscopy during atherogenesis in the rabbit. Atherosclerosis. 27:235251.

5. Davies, P. F., S. C. Selden, and S. M. Schwartz. 1980. Enhanced rates of fluid pinocytosis during exponential growth and regeneration by cultured arterial endothelial cells. J. Cell. Physiol. 102:119-127.

6. Gimbrone, M. A., Jr. 1980. Endothelial dysfunction and the pathogenesis of atherosclerosis. In Atherosclerosis V. A. M. Gotto, L. C. Smith, and B. Allen, editors. Springer-Verlag, New York. 415425.

7. Dewey, C. F., Jr., S. R. Bussolari, M. A. Gimbrone, Jr., and P. F. Davies. 1981. The dynamic response of vascular endothelial cells to fluid shear stress. J. Biomech. Engin. 103:177-185.

8. Bussolari, S. R., C. F. Dewey, Jr., and M. A. Gimbrone, Jr. 1982. Apparatus for subjecting living cells to fluid shear stress. Rev. Sci. Instrum. 53:1851-1854.

9. Bussolari, S. R. 1983. The dynamic effects of fluid shear stress on vascular endothelium in vitro. Ph.D. Thesis. Department of Mechanical Engineering, Massachusetts Institute of Technology, Cambridge, MA.

10. White, G. E., K. Fujiwara, E. J. Shefton, C. F. Dewey, Jr., and M. A. Gimbrone, Jr. 1982. Fluid shear stress influences cell shape and cytoskeletal organization in cultured vascular endothelium. Fed. Proc. 41:321.

11. White, G. E., M. A. Gimbrone, Jr., and K. Fujiwara. 1983. Factors influencing the expression of stress fibers in vascular endothelial cells in situ. J. Cell Biol. 97:416-424.

12. Stein, O., and Y. Stein. 1973. Lipid synthesis and degradation and lipoprotein transport in mammalian aorta. Ciba Found. Symp. 12:165-184.

13. Vasile, E., M. Simionescu, and N. Simionescu. 1983. Visualization of the binding, endocytosis and transcytosis of low density lipoprotein in the arterial endothelium in situ. J. Cell Biol. 96:1677-1689.

14. Jacques, P. J. 1972. Pathologic Aspects of Cellular Membranes. J. T. Dingle, H. B. Fell, editors. Academic Press, Inc., New York. 2:255282.

15. Davies, P. F., H. G. Rennke, and R. S. Cotran. 1981. Influence of molecular charge upon the endocytosis and intracellular fate of peroxidase activity in cultured arterial endothelium. J. Cell Sci. 49:69-86.

16. Gimbrone, M. A., Jr. 1976. Culture of vascular endothelium. In Progress in Hemostasis and Thrombosis. T. H. Spaet, editor. Grune and Stratton, New York. 3:1-28.

17. Steinman, R. M., and Z. A. Cohn. 1972. The interaction of soluble horseradish peroxidase with mouse peritoneal macrophages in vitro. J. Cell Biol. 55:186-204.

18. Davies, P. F., and R. Ross. 1978. Mediation of pinocytosis in cultured arterial smooth muscle and endothelial cells by platelet-derived growth factor. J. Cell Biol. 79:663-671.

19. Graham, R. C., and M. J. Karnovsky. 1966. The early stage of adsorption of injected horseradish peroxidase in the proximal tubule of 
the mass kidney: ultrastructural cytochemistry by a new technique. $J$. Histochem. Cytochem. 14:291-302.

20. Caro, C. G., J. M. Fitzgerald, and R. C. Schroter. 1971. Atheroma and arterial wall shear. Observation, correlation and proposal of a shear dependent mass transfer mechanism for atherogenesis. Proc. $R$. Soc. Lond. B. Biol. Sci. 177:109-159.

21. Dewey, C. F., Jr. 1979. Dynamics of Arterial Flow. Adv. Exp. Med. Biol. 115:55-103.

22. Fry, D. L. 1976. Hemodynamic forces in atherogenesis. In Cerebro Vascular Diseases. Raven Press. 77-95.

23. Glagov, S. 1972. Hemodynamic risk factors: mechanical stress, mural architecture, medial nutrition and the vulnerability of arteries to atherosclerosis. In The Pathogenesis of Atherosclerosis. R. W. Wissler, and J. C. Geer, editors. Williams and Watkins, Baltimore, 164-199.

24. Newman, D. L., J. R. Batten, and N. L. R. Bowden. 1977. Influence of experimental stenosis of uptake of albumin by the abdominal aorta. Atherosclerosis. 26:195-204.

25. Lutz, R. J., J. N. Cannon, K. B. Bischoff, R. L. Dedrick, R. K. Stiles, and D. L. Fry. 1977. Wall shear stress distribution in a model canine artery during steady flow. Circ. Res. 41:391-399.

26. Bjorkerud, S., and G. Bondjers. 1972. Endothelial integrity and viability in the aorta of the normal rabbit and rat as evaluated with dye exclusion tests and interference contrast microscopy. Atherosclerosis. 15:285-294.

27. Gutstein, W. H., G. A. Farrell, and C. Earmellini. 1973. Blood flow disturbance and endothelial cell injury in pre-atherosclerotic swine. Lab. Invest. 29:134-149.

28. Rittgers, S. E., P. E. Karayannacos, J. F. Guy, R. M. Nerem, G. M. Shore, J. R. Hostetler, and J. S. Vasko. 1978. Velocity distribution and intimal proliferation in autologous vein grafts in dogs. Circ. Res. 42:792-801.

29. Shepherd, J. T., and P. M. Vanhoutte. 1979. The Human Cardiovascular System. Raven Press, New York.
30. Smith, C. S. 1979. Investigating a possible shear stress mechanism for carotid atherogenesis. S. B. Thesis. Department of Mechanical Engineering, Massachusetts Institute of Technology, Cambridge, MA.

31. Mitchell, R. H., S. C. Ruff, and G. A. Murnaghan. 1978. Computer processing of long-term blood pressure and pulse rate variations. Proc. 2nd Int. Symp. on Ambulatory Monitoring (1SAM 1977). F. D. Stott, E. B. Raftery, P. Sleight, and L. Goulding, editors. Academic Press, London. 195-203.

32. Salisbury, J. L., J. S. Condeelis, and P. Satir. 1983. Receptormediated endocytosis: machinery and regulation of the clathrin-coated vesicle pathway. Int. Rev. Exp. Pathol. 24:1-88.

33. Steinman, R. M., S. E. Brodie, and Z. A. Cohn. 1976. Membrane flow during pinocytosis. A steriological analysis. J. Cell Biol. 68:665687.

34. Taylor, R. F., T. H. Price, S. M. Schwartz, and D. C. Dale. 1981. Neutrophilendothelial cell interactions on endothelial monolayers grown on micropore filters. J. Clin. Invest. 67:584-588.

35. Weinbaum, S., and S. Chien. 1980. Vesicular transport of macromolecules across vascular endothelium. In Mathematus of Microcirculation Phenomena. J. F. Cross and A. Popel, editors. Raven Press, New York. 109-141.

36. Pratten, M. K., and J. B. Lloyd. 1979. Effects of temperature, metabolic inhibitors and some other factors of fluid phase and adsorptive pinocytosis by rat peritoneal macrophages. Biochem. J. 180:567-571.

37. Duncan, R., and J. B. Lloyd. 1978. Pinocytosis in the rat visceral yolk sac. Effects of temperature, metabolic inhibitors and some other modifiers. Biochim. Biophys. Acta. 544:647-655.

38. Goldstein, J. L., and M. S. Brown. 1977. The low density lipoprotein pathway and its relation to atherosclerosis. Annu. Rev. Biochem. 46:897-930.

39. Truskey, G. A., C. K. Colton, and P. F. Davies. 1984. Kinetic analysis of receptor-mediated endocytosis and lysosomal degradation in cultured cells. Ann. NY Acad. Sci. In press. 